\title{
Correlation between Sensory Evaluation Scores and Flavor Attributes of Black Teas from Around the World
}

\author{
Duan $Y^{1,2}$, Song $X^{1,2}$, Yang $Y^{3}$, Li $L^{1,2}$, Zhao $Y^{1,2}$, Wang $Y^{1,2}$, Fang $W^{1,2^{\star}}$ and Zhu $X^{1,2^{\star}}$ \\ ${ }^{1}$ College of Horticulture, Nanjing Agricultural University, Nanjing, Jiangsu, P.R. China \\ ${ }^{2}$ Tea Science Research Institute, Nanjing Agricultural University, Nanjing, Jiangsu, P.R. China \\ ${ }^{3}$ Nanjing Rongdian Food Science and Technology Company Ltd, Nanjing, Jiangsu, P.R. China
}

\begin{abstract}
Background: Black teas can be grouped into many types based on cultivar, region of origin, harvesting seasons, processing methods and other factors, all of which combine to produce different flavor attributes (taste and aroma). This study aimed to establish and predict the quality of different black teas based on the correlation between sensory evaluation scores and the principal chemical components.

Results and Discussion: Sensory evaluation, analysis of the principal chemical components, as well as correlation analysis of black teas from around the world, were performed in this study. Statistical analysis showed that sensory scores were significantly and positively correlated with tea polyphenols, caffeine, amino acids, thearubigins and thearubigins/theaflavins ratio, and the correlation coefficient was $0.4166,0.6595,0.4379,0.4196,0.4165$, respectively, which determined black tea quality. Furthermore the taste quality showed a significant and positive correlation with caffeine, thearubigins and the ratio of thearubigins/theaflavins, which correlation coefficient was $0.4396,0.6109,0.4938$, respectively.
\end{abstract}

Conclusion: The aroma and taste of Chinese black teas were better than tea from other countries. The results may be attributed to the higher content of amino acids and caffeine in Chinese black teas.

Keywords: Black tea; Sensory quality; Chemical components; Correlation coefficient; Flavor comparison

\section{Introduction}

Tea (Camellia sinensis (L.) O. Kuntze) is a perennial crop and a very pleasant and popular beverage, which is consumed by over two-thirds of the world's population $[1,2]$. The world's tea production was around $5,561,339$ metric tons in 2014. China is the world's largest producer of tea, contributing $37.9 \%$ of the total global production, followed by India (21.7\%), Kenya (8.0\%), Sri Lanka (6.1\%), Vietnam (4.1\%), Turkey (4.1\%), Indonesia (2.7\%) and Iran (2.1\%) [3].

Black tea is the most prevalent type of tea in the world, which accounts for approximately $75 \%$ of the world's tea trade. Black tea is manufactured through processes including, withering, rolling (cutting), fermenting and drying [4]. Fermentation plays a crucial role in the manufacturing of black tea, during which the chemical components and subsequent taste, aroma, color, and nutritional and biological properties of teas are greatly altered [5,6]. Furthermore, the taste and flavor in the tea brewing process were influenced by polyphenols, caffeine, amino acids and other components [7]. The polyphenols were oxidized and transformed to form the black tea pigments, theaflavins (TF, golden yellow) and thearubigins (TR, orange brown), during the manufacturing process. TF and TR are mainly responsible for the brightness, briskness and color of tea and improve tea quality $[1,8,9]$. Furthermore, the formation of black tea cream when the tea infusion became cold was related to TR, TF and caffeine contents $[10,11]$. Previous work also showed that the formation of tea cream was regulated by various chemical interactions including polyphenolcaffeine interactions and complex polyphenol-polyphenol interactions. Polyphenol-caffeine complexation was influenced by a number of gallate and hydroxyl groups of the polyphenol [12]. In summary, polyphenols and caffeine are crucial components, which have a strong influence on the taste of black tea brew.

The quality of black tea depends on the chemical components of tea infusions and has traditionally been evaluated by a professional tea taster who has developed their own language to describe various quality attributes of the tea infusion [13]. The analytical methods available to identify chemical constituents impacting tea quality are precise [14], however, they are also complex, time consuming, labor-intensive, expensive and require large amounts of organic solvents. The use of organoleptic evaluation to identify tea quality is rapid but results may be inaccurate, and can be easily influenced by various factors, including the environment and the mood of the evaluator [15]. In this study, the quality of black tea was explored through the correlation of sensory scores and principal chemical components. Furthermore, the flavor attributes of tea samples from various countries were compared.

\section{Materials and Methods}

\section{Samples}

Thirty-seven teas, representing nine countries of origin, different manufacturing methods, varieties and prices were used in this study based on primary production regions for black tea. The black tea samples were collected from different countries including, China $(\mathrm{n}=22)$, Sri Lanka $(\mathrm{n}=5)$, Vietnam $(\mathrm{n}=2)$, Kenya $(\mathrm{n}=2)$, India $(\mathrm{n}=2)$, Nepal $(n=1)$, Malawi $(n=1)$, Indonesia $(n=1)$, Arabia $(n=1)$. There were 22 black tea samples from China, including samples from the southern Yangtze River area $(n=11)$, the southern China area $(n=9)$, the Southwest China area $(n=1)$, and the northern Yangtze River

*Corresponding author: Xujun Zhu and Wanping Fang, College of Horticulture, Nanjing Agricultural University, No. 1, Weigang, Nanjing-210095, Jiangsu, P.R. China, Tel/Fax: 8625-8439-5182; E-mail: zhuxujun@njau.edu.cn; fangwp@njau.edu.cn

Received March 09, 2018; Accepted March 30, 2018; Published April 06, 2018

Citation: Duan Y, Song X, Yang Y, Li L, Zhao Y, et al. (2018) Preparation and Evaluation of Carrot and Apple Blended Jam. J Food Process Technol 9: 726. doi: 10.4172/2157-7110.1000726

Copyright: (c) 2018 Duan Y, et al. This is an open-access article distributed under the terms of the Creative Commons Attribution License, which permits unrestricted use, distribution, and reproduction in any medium, provided the original author and source are credited. 
area $(n=1)$. Samples represented different manufacturing methods, including loose black tea of China that are coincident with Orthodox black tea and other countries, and CTC which is conventional black tea processed by cut, tear and curl methods. Details on samples collected are shown in Table 1.

\section{Chemicals}

Catechin, epicatechin, epigallocatechin, epigallocatechin gallate, epicatechingallate were purchased from Sigma-Aldrich (St. Louis, MO, USA). Methanol, acetic acid and ethanol were of HPLC-grade and were purchased from Honeywell (Morris, NJ, USA). Other reagents were of analytical grade.

\section{Sensory evaluation of black tea infusion}

According to GB/T23776-2009 [16], 3 g of each black tea sample was infused with $150 \mathrm{~mL}$ of freshly boiled water for $5 \mathrm{~min}$ in a tea pot. The black tea infusion was then filtrated through a stainless-steel strainer into a porcelain tea bowl.
Six highly trained tea tasting panelists, who had previously achieved Chinese national certificates as senior tea panelists, participated in this study. During the process of sensory evaluation, the panelists used the method of collective evaluation of tea quality grade [17]. Five factors of sensory evaluation, including dry leaf appearance, liquor color, aroma, taste and infused leaf appearance $[9,18]$. were determined (Table 2). In case of CTC (Crush, Tear and Curl) black tea, that is usually graded on one of four scales of quality (such as whole leaf, broken leaf, fannings and dust), and an infusion of CTC was poured on the tea pot cover which had been used to brew tea for evaluation [9].

\section{Polyphenols and caffeine analysis}

The tea infusion was filtered through a $0.45 \mu \mathrm{m}$ Millipore (Tianjin Branch billion Lung Experimental Equipment Co., Ltd) filter before determination using a HPLC system (Shimadzu LC-5P, Kyoto, Japan) fitted with a $\mathrm{C}_{18}$ column. The measurement was described as follows: flow rate: $1.0 \mathrm{~mL} \mathrm{~min}{ }^{-1}$; injection volume: $10 \mu \mathrm{L}$; mobile phase: $\mathrm{A}$ methanol, B: $98 \%$ water and $2 \%$ acetic acid; gradient elution: $20 \%-25 \%$ A, 0-1 min; $25 \%-45 \%$ A, 1-12 min; 45\%-90\% A, 12-15 min; 90\%-20\%

\begin{tabular}{|c|c|c|c|c|c|}
\hline No. & Classification & Sample name & Producing areas & Grade & Country \\
\hline CS001 & CTC & Uva tea & - & - & Sri Lanka \\
\hline CS002 & CTC & Vietnam tea & - & - & Vietnam \\
\hline CSO03 & CTC & Ceylon tea & - & - & Sri Lanka \\
\hline CS004 & CTC & Malawi tea & - & - & Malawi \\
\hline CS005 & CTC & Assam tea & - & - & India \\
\hline CS006 & CTC & Darjeeling tea & - & - & India \\
\hline CS007 & СTC & Nepal tea & - & - & Nepal \\
\hline CS008 & CTC & Kenya tea & - & - & Kenya \\
\hline CS009 & CTC & Indonesia tea & - & - & Indonesia \\
\hline CS010 & СТC & Earl Grey Tea & - & - & Sri Lanka \\
\hline CS011 & CTC & FV523 & - & - & Vietnam \\
\hline CS012 & CTC & Pure Kenya tea & - & - & Kenya \\
\hline CS013 & CTC & KANDY Tea & - & - & Sri Lanka \\
\hline CS035 & CTC & Arab tea & - & - & Arab \\
\hline CS036 & CTC & Ceylon tea & - & - & Sri Lanka \\
\hline CS014 & LBT & Lapsang souchong & SC & Grade 1 & China \\
\hline CS015 & LBT & Golden junmee & SC & - & China \\
\hline CS016 & LBT & Lapsang souchong & SC & Grade 1 & China \\
\hline CS017 & LBT & Golden junmee & SC & - & China \\
\hline CS018 & LBT & Panyong congou & SC & Special grade & China \\
\hline CS019 & LBT & Lapsang souchong & SC & Grade 1 & China \\
\hline CS020 & LBT & Panyong congou & SC & Special grade & China \\
\hline CS021 & LBT & Keemun tea & SYR & - & China \\
\hline CS022 & LBT & Keemun tea & SYR & - & China \\
\hline CS023 & LBT & Hainan tea & SC & - & China \\
\hline CS024 & LBT & Wild tea & SC & Grade 1 & China \\
\hline CS025 & LBT & Yunnan tea & SW & Special grade & China \\
\hline CS026 & LBT & Fuliang tea & SYR & Grade 1 & China \\
\hline CS027 & LBT & Jiangxi tea & SYR & Premium grade & China \\
\hline CS028 & LBT & Ninggong tea & SYR & Special grade & China \\
\hline CS029 & LBT & Jiangsu tea & SYR & - & China \\
\hline CS030 & LBT & Jiangsu tea & SYR & - & China \\
\hline CS031 & LBT & Jiangsu tea & SYR & Special grade & China \\
\hline CS032 & LBT & White leaf tea & SYR & Special grade & China \\
\hline CS033 & LBT & Xinyang tea & NYR & - & China \\
\hline CS034 & LBT & Hunan tea & SYR & Grade 1 & China \\
\hline CS037 & LBT & Zijuan tea & SYR & - & China \\
\hline
\end{tabular}

Table 1: Information on 37 black tea samples. 


\section{A, 15-16 min; maintained for 4 min.}

\section{Determination of free amino acids}

The content of free amino acids in the tea infusions was estimated with a spectrophotometer (Model UV-5800; Shanghai yuan Analytical Instrument Co., Ltd., China). The ninhydrin dying method was used as described by GB/T8314-2003 for determination of total amino acid content, which was established at $570 \mathrm{~nm}$, using glutamic acid as the standard.

\section{Determination of TF and TR}

Biochemical assessment of tea quality was carried out by estimation of TF and TR in black tea. A system analysis method for estimating TF, TR and TB in black tea was employed, using the simplified Roberts' method [19] as described previously [20], with slight modifications. The absorbance was measured on a UV spectrophotometer. The tea infusion was prepared by refluxing $3 \mathrm{~g}$ tea with $125 \mathrm{~mL}$ freshly boiled distilled water for $10 \mathrm{~min}$ on a water bath. The infusion $(30 \mathrm{~mL})$ was mixed with $30 \mathrm{~mL}$ ethyl acetate by shaking for $5 \mathrm{~min}$. On separation of the two phases, the bottom layer $\left(\mathrm{A}_{1}\right)$ was drained off and the ethyl acetate extract $\left(\mathrm{A}_{2}\right)$ contained the TF and part of TR. A quantity $(2 \mathrm{~mL})$ of the ethyl acetate extract $\left(A_{2}\right)$ was diluted with $25 \mathrm{~mL}$ ethanol $\left(E_{1}\right)$. The tea infusion $(15 \mathrm{~mL})$ was mixed with $15 \mathrm{~mL} \mathrm{~N}$-butyl alcohol by shaking for $3 \mathrm{~min}$. Then to $2 \mathrm{~mL}$ of the bottom layer $\left(\mathrm{B}_{1}\right), 2 \mathrm{~mL}$ of aqueous saturated oxalic acid solution and $6 \mathrm{~mL}$ of water was added, and it was made up to $25 \mathrm{~mL}$ with ethanol $\left(\mathrm{E}_{2}\right)$. The ethyl acetate extract $(15 \mathrm{~mL}$, $\mathrm{A}_{2}$ ) was mixed with $15 \mathrm{~mL}$ aqueous $2 \%$ sodium bicarbonate by shaking for $30 \mathrm{~s}$ and left aside. On separation of the two phases, the bottom layer $\left(C_{1}\right)$ was drained off and the ethyl acetate extract $\left(C_{2}\right)$ contained the TF. A quantity $(4 \mathrm{~mL})$ of ethyl acetate extract $\left(\mathrm{C}_{2}\right)$ was diluted with 25 $\mathrm{mL}$ of ethanol $\left(\mathrm{E}_{3}\right)$. To $2 \mathrm{~mL}$ of the bottom layer $\left(\mathrm{A}_{1}\right), 2 \mathrm{~mL}$ of aqueous saturated oxalic acid solution and $6 \mathrm{~mL}$ water was added and it was made up to $25 \mathrm{~mL}$ with ethanol $\left(\mathrm{E}_{4}\right) . \mathrm{E}_{1}, \mathrm{E}_{2}, \mathrm{E}_{3}, \mathrm{E}_{4}$ were measured at 380 $\mathrm{nm}$ with a spectrometer. The tea pigments were calculated as follows:

$$
\begin{aligned}
& \operatorname{TF}(\%)=\mathrm{E}_{3} \times 2.25 \\
& \operatorname{TR}(\%)=\left(2 \times \mathrm{E}_{1}+2 \times \mathrm{E}_{4}-\mathrm{E}_{3}-2 \times \mathrm{E}_{2}\right) \times 7.06 \\
& \operatorname{TB}(\%)=2 \times \mathrm{E}_{2} \times 7.06
\end{aligned}
$$

\section{Statistical analysis}

Results are presented as mean values (at least 3 replicates), the statistical significance of the sensory attributes and chemical components of black tea was evaluated by nonparametric testing at a $5 \%$ significance level and 1\% significance level (Microsoft Office 2010). Differences were considered to be significant at $\mathrm{p} \leq 0.05$, and to be extremely significant at $\mathrm{p} \leq 0.01$.

\section{Results and Discussion}

\section{Analysis of sensory evaluation and quality scores of tea samples}

Full-type black tea from China and broken-type tea from other countries was collected and sensory evaluation analyses were performed. The aroma of Chinese black tea was relatively better than tea from other countries, and included some unique aroma characters, such as the orchid fragrance in CS020, the sugar aroma of CSO25, smoky flavor of CS019, and the aroma of high sharpness persisting (Tables 3 and 4). The aroma characters of black tea samples collected from other countries were mainly sweet and fruity fragrances, and a slightly flat aroma. The durability of aroma from Chinese black tea was better than that from other samples. In addition, Sri Lankan Black Tea (CS036) was only one sample from other countries had a floral scent.

The tea infusion color of Assam black tea (CS005) was especially good in redness and brightness, and the evaluation score of liquor was the highest of all the black tea samples, after sensory evaluation scores. The score of tea liquor of Malawi black tea (CS004) was the lowest of all the samples, and the liquor had a deep red and dark color. The sensory evaluation results of the tea liquor samples from other countries indicated no significant differences. However, the tea liquor from the southern Yangtze River and the northern Yangtze River were mostly orange-yellow in color, while a yellow tea infusion was not apparent in teas from other areas in China. The degree of redness of black teas from the southern and the northern Yangtze River areas was slightly weaker than that found in teas from other areas in China and from other countries in the world, and this may be due to the different tea cultivars and the degree of fermentation used. The liquor color of teas from the southern and the northern Yangtze River areas were mostly orange in color. The quantities of TF and TR produced largely govern the liquor characters (color, brightness, briskness, strength and 'quality') of teas [21,22]. It is therefore likely that the degree of the withering conducted on the tea leaf may influence the development of liquor characters and the overall quality of black teas [4].

The briskness, umami and strength of infusion were the most important factors for evaluating the taste of black tea. The umami taste of Chinese black teas (except CS030) was better than that of teas from other countries. From Table 3, it can be seen that the umami taste of CS016, CS020, CS021, CS025, CS026, CS028, CS033 and CS037 was relatively high, while the umami taste scores of Chinese black tea (CS030), Vietnamese black tea (CS002) and Kenyan black tea (CS012) was the lowest. Furthermore, the briskness and strength of Assam black tea and Nepal black tea were the best.

In particular, the difference in tea taste between tea samples may have been due to the different manufacturing methods employed. Chinese black tea is mainly full-type black tea, while the black tea from the other countries is mainly broken-type tea (crush, tear and curl) [2325].

\section{Analysis of chemical constituents in tea samples}

The variation in content of polyphenols in Chinese black tea samples was relatively larger than that in other samples, and although there was no obvious trend, the content of polyphenols in sample CS037 was higher than in other samples. Sample CS037 was made from a purple leaf cultivar, named 'Zijuan', which is a specific cultivar in Yunnan big-leaf tea population with a national improved tea variety, Menghai big-leaf tea, which has high levels of tea ployphenols (TPs) [26], and good pharmacological effects [27]. Moreover, the polyphenol content in Vietnamese Black Teas, CS002 and CS011, was lower than that in samples from other countries. The polyphenol content was highest in tea samples CS005 and CS006, which were from India (except CS037).

\begin{tabular}{|c|c|c|c|c|}
\hline Classification & Appearance & Liquor & Aroma & Taste \\
\hline Loose black tea & 25 & 10 & 25 & 30 \\
\hline CTC & 20 & 10 & 30 & 10 \\
\hline
\end{tabular}

Table 2: The proportion of five factors in different types of black tea 


\begin{tabular}{|c|c|c|c|}
\hline No. & Aroma & Liquor & Taste \\
\hline \multicolumn{4}{|c|}{ China } \\
\hline CS014 & Sweet and flower fragrance, umami, lasting & $\begin{array}{c}\text { Orange and redness, clarity and } \\
\text { brightness }\end{array}$ & Sweet and mellow, umami \\
\hline CS015 & Sweet and potato fragrance, lasting & $\begin{array}{c}\text { Orange and redness, clarity and } \\
\text { brightness }\end{array}$ & Longan flavour, slightly umami \\
\hline CS016 & Longan fragrance, lasting & $\begin{array}{l}\text { Orange and redness, clarity and } \\
\text { brightness }\end{array}$ & Longan flavour, umami \\
\hline CS017 & Caramel-like, slightly lasting & Redness, brightness & More mellow, slightly taster-after \\
\hline CS018 & Longan fragrance, slightly lasting & Redness, brightness & Mellow, umami \\
\hline CS019 & Smoke-like, lasting & Orange and redness, clarity & Mellow, smoked odour, little umami \\
\hline CS020 & Sweet and orchid fragrance $\square$ high and lasting & $\begin{array}{c}\text { Orange and redness, clarity and } \\
\text { brightness }\end{array}$ & More mellow, umami \\
\hline CS021 & Sweet and fruity fragrance, slightly high and lasting & $\begin{array}{l}\text { Orange and redness, clarity and } \\
\text { brightness }\end{array}$ & Mellow, umami \\
\hline CS022 & $\begin{array}{l}\text { Sweet fragrance, stuffy smell, none high and none } \\
\text { lasting }\end{array}$ & Redness, brightness & Mellow, slightly umami \\
\hline CS023 & Sweet and loquat fragrance, high and lasting & Redness, brightness & Briskness and strength, little umami \\
\hline CS024 & Stuffy smell, none high and none lasting & Deep redness, slightly brightness & $\begin{array}{c}\text { More mellow, slightly taster-after, slightly } \\
\text { umami }\end{array}$ \\
\hline CS025 & Sweet and sugar-like, high and lasting & $\begin{array}{c}\text { Orange and redness, clarity and } \\
\text { brightness }\end{array}$ & Sweet and mellow, umami \\
\hline CS026 & Sweet and flower fragrance, high and lasting & Redness, clarity & More mellow, umami \\
\hline CS027 & Potato fragrance, slightly high and slightly lasting & Redness, slightly brightness & More mellow, slightly umami \\
\hline CS028 & $\begin{array}{l}\text { Sweet and flower fragrance, slightly high and little } \\
\text { lasting }\end{array}$ & $\begin{array}{l}\text { Orange and redness, clarity and } \\
\text { brightness }\end{array}$ & Mellow, umami \\
\hline CS029 & Sweet and little smoked, slightly lasting & Redness, little brightness & More mellow, little umami \\
\hline CS030 & Sweet fragrance, slightly high and slightly lasting & Redness, little brightness & More mellow, none umami \\
\hline CS031 & Sweet fragrance, little lasting & Orange yellow little, brightness & Mellow, little umami \\
\hline CS032 & Sweet and little flower fragrance & Orange yellow, clarity and brightness & Mellow, little umami \\
\hline CS033 & Sweet and longan fragrance & Golden yellow, most clarity and brightness & More mellow, umami, astringency \\
\hline CS034 & potato fragrance & Golden yellow, clarity and brightness & More mellow, little umami \\
\hline CS037 & Sweet fragrance, slightly high and slightly lasting & Orange yellow, clarity and brightness & Sweet and mellow, umami \\
\hline \multicolumn{4}{|c|}{ Other countries } \\
\hline CS001 & Sweet and little rose fragrance & Redness, little brightness & Pure, little umami, little strength \\
\hline CS002 & sweet fragrance and staleness odour, slightly lower & Deep redness, little brightness & Flat and staleness flavour, none umami \\
\hline CS003 & Stuffy smell & Deep redness, slightly brightness & Mellow, little umami \\
\hline CS004 & Staleness odour & Deep redness, little dark & More mellow, slightly strength, little umami \\
\hline CS005 & Sweet fragrance, pure, little high & Redness, clarity and brightness & Briskness and strength, slightly umami \\
\hline CS006 & Chinese herbaceous peony fragrance, flat & $\begin{array}{c}\text { Orange and redness, clarity and } \\
\text { brightness }\end{array}$ & More mellow, slightly umami \\
\hline CS007 & Sweet fragrance, flat & Redness, little brightness & Briskness and strength, little umami \\
\hline CS008 & Sweet fragrance, flat & Deep redness, little brightness & Mellow, little staleness flavour little umami \\
\hline CS009 & Sweet fragrance, little staleness odour, flat & Redness, clarity & Mellow, staleness flavour, little umami \\
\hline CS010 & Bergamot odour, high & Redness, brightness & Mellow, fries flavour, slightly umami \\
\hline CS011 & Sweet fragrance, little staleness odour & Orange and redness, slightly brightness & Pure, little umami \\
\hline CS012 & Sweet and little caramel fragrance, little high & Redness, slightly brightness & Flat flavour, none umami \\
\hline CS013 & Sweet fragrance, flat & Redness, little brightness & Mellow, little umami \\
\hline CS035 & Sweet fragrance and bergamot odour, soft and high & Deep redness, little brightness & More mellow, slightly sour \\
\hline CS036 & $\begin{array}{l}\text { Sweet and flower fragrance, slightly high and slightly } \\
\text { lasting }\end{array}$ & Orange and redness, slightly brightness & More mellow, slightly umami \\
\hline
\end{tabular}

Table 3: The sensory evaluation of different black teas.

The polyphenols content in Sri Lanka's black tea samples were similar to the polyphenol levels in Chinese black tea (Table 5).

Caffeine is an important flavor substance in black tea infusion and is responsible for the stimulating effect of tea liquor [9]. The caffeine content of Chinese tea samples was higher than that in teas from other countries, probably due to differences in tea varieties and processing methods as caffeine content did not significantly change during the processing of black tea [28]. In addition, the caffeine content in tea samples from the southern Yangtze River area was not significantly different (Table 5). Furthermore, sample CS036 from Sri Lanka was significantly higher in caffeine content which was $9.01 \%$.

Free amino acids in tea can play an essential role in tea aroma and taste qualities [29] and are major contributors to the freshness of tea [30]. The amino acid content in tea samples from the southern Yangtze River area in China was higher than that in teas produced in other areas in China or in other countries. This southern Yangtze River area is a major tea production area, due to the occurrence of optimum climatic conditions, such as mild temperatures, abundant rainfall, high humidity 


\begin{tabular}{|c|c|c|c|c|c|c|}
\hline No. & Appearance & Aroma & Liquor & Taste & Infuse leaves & Total score \\
\hline \multicolumn{7}{|c|}{ China } \\
\hline CS014 & 22.5 & 22.5 & 8.5 & 25.5 & 7.25 & 86.25 \\
\hline CS015 & 21.25 & 22.5 & 8.65 & 25.5 & 8 & 85.9 \\
\hline CS016 & 20 & 22.5 & 8.5 & 27 & 7.25 & 85.25 \\
\hline CS017 & 21.25 & 20 & 9.15 & 25.5 & 8 & 83.9 \\
\hline CS018 & 20 & 20 & 9 & 24 & 7.75 & 80.75 \\
\hline CS019 & 18.75 & 21.25 & 8 & 24 & 7.25 & 79.25 \\
\hline $\mathrm{CS} 020$ & 20 & 23.75 & 8.5 & 27 & 8.5 & 87.75 \\
\hline CS021 & 19.38 & 22.5 & 8.5 & 27 & 8.5 & 85.88 \\
\hline CS022 & 20 & 19.38 & 9 & 25.5 & 7 & 80.88 \\
\hline CS023 & 21.25 & 22.5 & 8.75 & 24 & 9 & 85.5 \\
\hline CS024 & 20 & 17.88 & 8.5 & 25.5 & 8 & 79.88 \\
\hline CS025 & 21.25 & 22.5 & 8.5 & 27 & 7.4 & 86.65 \\
\hline CS026 & 22.25 & 22.5 & 8 & 27 & 9 & 88.75 \\
\hline CS027 & 22.5 & 21.38 & 8.5 & 25.5 & 8 & 85.88 \\
\hline CS028 & 21.25 & 22.5 & 8.25 & 27 & 8 & 87 \\
\hline CS029 & 20 & 20.63 & 8.3 & 23.25 & 8.15 & 80.33 \\
\hline CS030 & 21.25 & 21.25 & 8.15 & 21 & 8.5 & 80.15 \\
\hline CS031 & 21.25 & 21 & 7.9 & 24 & 8.5 & 82.65 \\
\hline CS032 & 22.5 & 22.5 & 8.5 & 25.5 & 8.65 & 87.65 \\
\hline CS033 & 21.25 & 21.25 & 9 & 27 & 7.75 & 86.25 \\
\hline CS034 & 21.25 & 21.25 & 8.5 & 25.2 & 8.3 & 84.5 \\
\hline CS037 & 22.5 & 23.75 & 7.9 & 27 & 8 & 89.15 \\
\hline \multicolumn{7}{|c|}{ Other countries } \\
\hline CS001 & 16 & 25.5 & 7.9 & 24 & 8 & 81.4 \\
\hline CS002 & 16 & 22.95 & 8 & 21 & 7 & 74.95 \\
\hline CS003 & 16 & 21 & 8.4 & 24 & 7.5 & 76.9 \\
\hline CS004 & 15 & 21.3 & 7 & 24 & 7.5 & 74.8 \\
\hline CS005 & 16 & 25.5 & 9.25 & 26.25 & 8 & 85 \\
\hline CS006 & 14 & 25.5 & 8.85 & 26.4 & 8 & 82.75 \\
\hline CS007 & 14.5 & 24 & 8.8 & 25.5 & 8 & 80.8 \\
\hline CS008 & 16 & 24.75 & 8 & 24 & 7 & 79.75 \\
\hline CS009 & 15 & 22.5 & 8.4 & 22.5 & 7.5 & 75.9 \\
\hline CS010 & 17 & 25.5 & 8.5 & 22.5 & 7.75 & 81.25 \\
\hline CS011 & 16 & 23.25 & 8 & 25.5 & 8 & 80.75 \\
\hline CS012 & 16 & 25.5 & 8.25 & 21 & 7 & 77.75 \\
\hline CS013 & 15.6 & 24 & 8 & 24.75 & 8 & 80.35 \\
\hline CS035 & 17 & 24 & 8 & 23.25 & 8 & 80.25 \\
\hline CS036 & 18 & 26.25 & 8 & 25.5 & 7.5 & 85.25 \\
\hline
\end{tabular}

Notes: Tea samples conduct two sensory evaluation of different times of the same day, the scores are calculated according to score coefficient of table 2

Table 4: The scores of individual attributes of sensory evaluation.

and moderate sunshine [31]. Hence, the high content of amino acids in the teas was mainly due to the suitable climatic characteristics. The amino acid content was highest in sample CS032, which was made from a white-leaf cultivar. White-leaf is a typical albino tea cultivar found in China that has a high level of amino acids, which are essential components affecting tea taste quality [32]. The content of amino acids in the Vietnamese black teas, CS002 and CS011, were relatively lower, compared to samples from other countries, and amino acids contents in the Kenyan sample CS008 was the lowest. In addition, the amino acid levels in black teas from China were similar to levels in Sri Lankan teas. However, amino acids contents in Chinese black teas were higher than in Sri Lankan teas due to geographical locations [33], which were similar to results reported in previous studies [34,35].

There was no obvious difference in TF content or in the TR/TF ratio between samples (Table 5). The TR content in samples CS005 and CS006 from India were the highest, while sample CS009 from Indonesia had the lowest, which was consistent with the liquor and taste of tea samples (Table 3). The TR contents in samples from the Southern China area were higher than those in other tea producing areas, while CS030 and CS031 from the southern Yangtze River area had lower TR contents than other samples from the same area. This may be due to differences in the production processes employed. In addition, the highest TB content was in Sri Lankan tea samples. Black tea pigment is a key factor in forming the color and taste of tea infusion, and polyphenols in fresh tea leaves are consumed and chemically transformed into various oxidation products including dimeric, oligomeric and polymeric constituents, such as TF, theasinensins, TR and TB [36,37]. TF mainly determine the brightness of the tea infusion, with higher levels of TF forming better brightness. The TR level is mainly related to liquor and concentration and is a very important chemical component with regard to taste and concentration of tea infusion. In general, TB have a negative impact on black tea quality, with high contents resulting in the tea infusion becoming dark in color and losing astringency properties, while moderate levels of TB are essential to form the red infusion of black tea. The TR/TF ratio is another important factor in determining the quality of black tea, which levels ranging from 10 to 12 resulting in balanced liquor and taste [38]. 
Citation: Duan Y, Song X, Yang Y, Li L, Zhao Y, et al. (2018) Preparation and Evaluation of Carrot and Apple Blended Jam. J Food Process Technol 9: 726 . doi: 10.4172/2157-7110.1000726

Page 6 of 9

\section{Correlation analysis between tea liquor, taste and pigments}

The relevance of sensory score of black tea color, taste and tea pigments (TF, TR and TB) was performed through correlation coefficient statistical analysis. Table 6 shows that the correlation coefficient of sensory quality (liquor and taste) and tea pigments had a correlation. The score of tea liquor was extremely significant and positive correlation with TR content, which correlation coefficient was 0.5839 , TF content and the TR/TF value with tea liquor`s correlation coefficient was 0.3028 and 0.2122 , only showed positive correlation. However, TB showed a negative correlation with tea liquor score. Therefore, it is feasible to employ the TR content to reflect the color of black tea infusion. In addition, there were extremely positive and significant correlations between tea taste scores and TR content and $\mathrm{TR} / \mathrm{TF}$ values, the correlation coefficient was 0.6109 and 0.4938 , respectively. However, the TB content showed a significantly negative correlation with tea taste. The results imply that the TR content and TR/ TF values could be used to evaluate the taste quality of black tea.

\section{Correlation analysis of tea taste, polyphenols and caffeine}

The correlation coefficients of tea polyphenols, caffeine and black tea taste scores are shown in Table 7 . The tea taste scores were positively correlated with contents of polyphenols and caffeine, indicating that determination of polyphenols and/or caffeine contents can assay black tea taste.

\section{Correlation analysis of tea taste, aroma and amino acids}

As shown in Table 8, the amino acid contents were positively correlated with tea taste and aroma scores. Therefore, amino acids levels can also be considered as important chemical components to estimate tea taste and aroma.

In particular, the aroma and taste characteristics of Chinese black tea were better than tea from other countries, while the black tea liquor from all samples were not significantly different. A possible explanation is that Chinese full-type black tea is usually brewed with freshly boiled water and is drank directly, whereas milk and sugar may be added to broken-type black tea infusion during consumption [39-41]. Although

\begin{tabular}{|c|c|c|c|c|c|c|c|}
\hline No. & Polyphenols & Caffeine & Amino acids & Theaflavins & Thearubigins & Theabrownins & TR/TF \\
\hline \multicolumn{8}{|c|}{ China } \\
\hline CS014 & 14.81 & 6.07 & 0.13 & 1.02 & 10.69 & 8.7 & 10.48 \\
\hline CS015 & 20.77 & 9.89 & 0.36 & 1.04 & 12.93 & 4.14 & 12.43 \\
\hline CS016 & 12.54 & 8.54 & 0.25 & 1.5 & 15.09 & 5.72 & 10.06 \\
\hline CS017 & 12.64 & 6.46 & 0.34 & 0.94 & 10.16 & 7.47 & 10.81 \\
\hline CS018 & 15.76 & 7.55 & 0.27 & 1.24 & 13.75 & 5.87 & 11.09 \\
\hline CS019 & 10.41 & 4.91 & 0.18 & 0.72 & 11.3 & 4.76 & 15.69 \\
\hline CSO20 & 14.02 & 6.64 & 0.45 & 0.93 & 10.11 & 5.27 & 10.87 \\
\hline CS021 & 17.66 & 7.73 & 1.08 & 1.05 & 13.59 & 5.39 & 12.94 \\
\hline CSO22 & 13.2 & 7.21 & 0.76 & 1.08 & 13.52 & 7.6 & 12.52 \\
\hline CS023 & 28.28 & 8.43 & 0.52 & 0.99 & 12.07 & 7.16 & 12.19 \\
\hline CSO24 & 15.13 & 7.9 & 0.56 & 1.26 & 13.16 & 7.37 & 10.44 \\
\hline CS025 & 26.16 & 8.69 & 0.48 & 0.91 & 12.95 & 5.69 & 14.23 \\
\hline CS026 & 20.8 & 8.36 & 1.06 & 1.02 & 11.36 & 7.88 & 11.14 \\
\hline CS027 & 17.36 & 7.13 & 0.75 & 0.8 & 10.65 & 6.38 & 13.31 \\
\hline $\mathrm{CS} 028$ & 17.4 & 7.21 & 0.92 & 0.98 & 12.18 & 7.79 & 12.43 \\
\hline CS029 & 17.78 & 7.06 & 0.66 & 1.25 & 10.87 & 6.75 & 8.7 \\
\hline CS030 & 18.68 & 7.74 & 0.55 & 1.03 & 8.66 & 8.02 & 8.41 \\
\hline CS031 & 17.82 & 7.36 & 0.97 & 0.67 & 8.26 & 5.93 & 12.33 \\
\hline CS032 & 17.73 & 6.54 & 1.24 & 1.34 & 14.74 & 4.39 & 11 \\
\hline CS033 & 13.66 & 7.56 & 0.71 & 1.36 & 13.72 & 5.78 & 10.09 \\
\hline CS034 & 21.55 & 7.72 & 0.74 & 1.12 & 11.48 & 4.21 & 10.25 \\
\hline CS037 & 31.73 & 7.79 & 0.48 & 0.78 & 10.18 & 4.94 & 13.05 \\
\hline \multicolumn{8}{|c|}{ Other countries } \\
\hline CS001 & 15.8 & 4.86 & 0.24 & 0.72 & 7.77 & 7.78 & 10.79 \\
\hline CS002 & 11.86 & 5.44 & 0.19 & 0.68 & 7.85 & 7.85 & 11.54 \\
\hline CS003 & 16.58 & 4.39 & 0.12 & 1.11 & 12.32 & 9.26 & 11.1 \\
\hline CS004 & 14.73 & 5.05 & 0.33 & 0.84 & 9.57 & 8.98 & 11.39 \\
\hline CS005 & 17.52 & 5.94 & 0.46 & 1.05 & 16.3 & 8.74 & 15.52 \\
\hline CS006 & 24.02 & 6.72 & 0.19 & 1.15 & 13.8 & 2.95 & 12 \\
\hline CS007 & 25.53 & 5.05 & 0.37 & 1.13 & 12.52 & 7.24 & 11.08 \\
\hline CS008 & 18.15 & 5.37 & 0.09 & 1.33 & 10.31 & 5.65 & 7.75 \\
\hline CS009 & 15.63 & 4.44 & 0.75 & 0.96 & 6.18 & 7.06 & 6.44 \\
\hline CS010 & 17.51 & 6.2 & 0.46 & 1.35 & 11.75 & 5.79 & 8.7 \\
\hline CS011 & 10.25 & 5.88 & 0.23 & 1.62 & 12.29 & 5.21 & 7.59 \\
\hline CS012 & 17.04 & 5.64 & 0.54 & 1.24 & 8.23 & 7.7 & 6.64 \\
\hline CS013 & 17.72 & 5.48 & 0.16 & 1.36 & 11.24 & 9.45 & 8.26 \\
\hline CSO35 & 14.52 & 5.73 & 0.24 & 0.83 & 5.75 & 9.05 & 6.93 \\
\hline CS036 & 26.86 & 9.01 & 0.79 & 0.8 & 9.3 & 5.62 & 11.63 \\
\hline
\end{tabular}

Table 5: Determination of the chemical components (\%) in different black teas. 
Citation: Duan Y, Song X, Yang Y, Li L, Zhao Y, et al. (2018) Preparation and Evaluation of Carrot and Apple Blended Jam. J Food Process Technol 9: 726 . doi: $10.4172 / 2157-7110.1000726$

Page 7 of 9

\begin{tabular}{|c|c|c|c|c|c|}
\hline Variables & Liquor score & Taste score & Theaflavins & Thearubigins & \\
\hline Liquor score & 1 & & & \\
\hline Taste score & 0.3002 & 1 & 1 & \\
\hline Theaflavins & 0.3028 & 0.1159 & 0.5384 & 1 \\
\hline Thearubigins & $0.5839^{* *}$ & $0.6109^{* *}$ & -0.1521 & -0.3118 & 1 \\
\hline Theabrownins & -0.1874 & $-0.3327^{*}$ & -0.4757 & 0.4651 & -0.2127 \\
\hline TR/TF & 0.2122 & $0.4938^{* *}$ & & 1 \\
\hline
\end{tabular}

Table 6: The correlation coefficient between sensory quality (liquor and taste) and black tea pigment.

\begin{tabular}{|c|c|c|c|}
\hline Variables & Taste score & Polyphenols \\
\hline Taste score & 1 & - & Caffeine \\
\hline Polyphenols & 0.2232 & 1 & -- \\
\hline Caffeine & $0.43966^{* *}$ & 0.4331 \\
\hline${ }^{*} \mathrm{P}<0.05 ;{ }^{* *} \mathrm{P}<0.01$ & & 1 \\
\hline
\end{tabular}

Table 7: The correlation coefficient of black tea taste score and chemical components (polyphenols and caffeine).

\begin{tabular}{|c|c|c|c|}
\hline Variables & Taste score & Aroma score \\
\hline Taste score & 1 & - & Amino acids \\
\hline Aroma score & 0.4528 & - \\
\hline Amino acids & 0.2396 & 0.3108 \\
\hline${ }^{*} \mathrm{P}<0.05 ;{ }^{*} \mathrm{P}<0.01$ & & 1 \\
\hline
\end{tabular}

Table 8: The correlation coefficient between sensory quality (taste and aroma) and amino acids.

\begin{tabular}{|c|c|c|c|c|c|c|c|c|}
\hline Variables & $\begin{array}{l}\text { Sensory evaluation } \\
\text { score }\end{array}$ & Polyphenols & Caffeine & Amino acids & Theaflavins & Thearubigins & Theabrownins & TR/TB \\
\hline $\begin{array}{l}\text { Sensory evaluation } \\
\text { score }\end{array}$ & 1 & -- & -- & -- & -- & -- & -- & -- \\
\hline Polyphenols & $0.4166^{* *}$ & 1 & -- & -- & -- & -- & -- & -- \\
\hline Caffeine & $0.6595^{* *}$ & 0.4331 & 1 & -- & -- & -- & -- & -- \\
\hline Amino acids & $0.4379^{* *}$ & 0.2008 & 0.4183 & 1 & -- & -- & -- & -- \\
\hline Theaflavins & -0.0042 & -0.1812 & 0.0422 & -0.0749 & 1 & -- & -- & -- \\
\hline Thearubigins & $0.4196^{* *}$ & 0.073 & 0.354 & 0.1067 & 0.5384 & 1 & -- & -- \\
\hline Theabrownins & $-0.3943^{*}$ & -0.2491 & -0.4198 & -0.1912 & -0.1521 & -0.3118 & 1 & -- \\
\hline $\mathrm{TR} / \mathrm{TF}$ & $0.4165^{* *}$ & 0.2388 & 0.2943 & 0.1492 & -0.4757 & 0.4651 & -0.2127 & 1 \\
\hline
\end{tabular}

Table 9: The correlation coefficient between sensory quality and chemical compositions.

the aroma and taste of the broken-type tea were relatively lower, the taste could be improved via addition of other substances, which may mask the original taste of the tea. Therefore, Chinese black tea aroma and taste are quite important for tea quality formation, and the appearance of dry tea is also an essential factor in the evaluation of tea quality.

\section{Correlation analysis between sensory quality and chemical composition of black tea}

The correlation between the sensory quality of black tea and the chemical composition is shown in Table 9. The sensory quality score was extremely significant and positively correlated with the content of tea polyphenols, caffeine, amino acids, TR and TR/TF, which correlation coefficient was $0.4166,0.6595,0.4379,0.4196,0.4165$, respectively. There was a significant and negative correlation between the TB content and sensory evaluation scores. Surprisingly, TF showed a negative correlation with the sensory quality of black tea. However, there was a positive correlation between the tea taste, color and TF (Table 6). It may be that the appearance, aroma and infusion of black tea impacted the sensory quality scores, or they may have been impacted by other factors. Therefore, the effect of TF on the sensory quality of black tea warrants further investigation.

Moreover, the comprehensive effects of these chemical compounds in forming the unique quality of black tea needs to be studied further, including their effects on high and lasting aroma, mellowness, umami taste, astringency, sweet taste, redness and brightness of liquor etc. [42-50]. TF is an important chemical component of the color and taste quality of black tea infusion, which was positively correlated with the quality of the liquor and taste of black tea [35,51].

\section{Conclusion}

In summary, a comprehensive analysis of 37 different black tea samples from nine countries was performed. The aroma and taste of Chinese black teas were better than teas from other countries, with the aroma of sharpness persisting from Chinese black tea. Teas from other countries had mainly sweet and fruity fragrances, but the aroma of teas from other countries was also slightly flat. The liquor colors of teas from 
the southern and northern regions of the Yangtze River were mostly orange in color. The umami tastes of Chinese black teas were better than those from other countries, and the umami tastes of teas from Vietnam and Kenya were relatively lower. This study indicated that the evaluated sensory scores were extremely significant and positively correlated with tea polyphenols, caffeine, amino acids and TR/TF values.

\section{Acknowledgements}

The authors thank Profs Lucheng Yang for performing sensory evaluation of tea samples. This work was supported by National Natural Science Foundation of China (31370688, 31400584), The earmarked fund for China Agriculture Research System (CARS-19), Modern Agriculture Industry System in Jiangsu (SXGC[2017]279), Keypoint Research and Invention Program of Jiangsu Province (BE2016417) and FuJian Province "2011 Collaborative Innovation Center" Chinese Oolong Tea Industry Innovation Center (Cultivation) special project (J2015-75).

\section{References}

1. Bhuyan LP, Hussain A, Tamuly P, Gogoi RC, Bordoloi PK, et al. (2009) Chemical characterization of CTC black tea of northeast India: Correlation of quality parameters with tea tasters' evaluation. J Sci Food Agric 89: 1498-1507.

2. Gupta S, Saha B, Giri AK (2002) Comparative antimutagenic and anticlastogenic effects of green tea and black tea: A review. Mutat Res 512: 37-65.

3. FAO (2017) FAOSTAT: Tea production 2014. FAO, Rome, Italy.

4. Ullah MR, Gogoi N, Baurah D (1984) Effect of withering on fermentation of tea leaf and development of liquor characters of black tea. J Sci Food Agric 35: 1142-147.

5. Tan J, Dai W, Lu M, Lv H, Guo L, et al. (2016) Study of the dynamic changes in the non-volatile chemical constituents of black tea during fermentation processing by a non-targeted metabolomics approach. Food Res Int 79: 106113.

6. Shinde A, Das S, Datta AK (2013) Quality improvement of orthodox and CTC tea and performance enhancement by hybrid hot air-radio frequency (RF) dryer. J Food Eng 116: 444-449.

7. Khanum H, Faiza S, Sulochanamma G, Borse BB (2017) Quality, antioxidant activity and composition of Indian black teas. J Food Sci Technol 54: 1266-1272.

8. Higdon JV, Frei B (2003) Tea catechins and polyphenols: Health effects, metabolism and antioxidant function. Crit Rev Food Sci 43: 89-143.

9. Kumar RS, Muraleedharan NN, Murugesan S, Kottur G, Anand MP, et al. (2011) Biochemical quality characteristics of CTC black teas of south India and their relation to organoleptic evaluation. Food Chem 129: 117-124.

10. Roberts EAH (1963) The phenolic substances of manufactured tea: $X$. The cream down of the liquors. J Sci Food Agric 14: 700-770.

11. Smith RF (1968) Studies on the formation and composition of tea 'cream' in tea infusions. J Sci Food Agric 19: 530-534.

12. Yin JF, Xu YQ, Yuan HB, Luo LX, et al. (2009) Cream formation and main chemical components of green tea infusions processed from different parts of new shoots. Food Chem 114: 665-670.

13. Bhuyan LP, Sabhapondit S, Baruah BD, Bordoloi C, Gogoi R, et al. (2013) Polyphenolic compounds and antioxidant activity of CTC black tea of NorthEast India. Food Chem 141: 3744-3751.

14. Sharma M, Ghosh D, Bhattacharya N (2013) Electronic nose: A new way for predicting the optimum point of fermentation of black tea. Int J Eng Sci Inv 2: 56-60.

15. Ning J, Sun J, Zhu X, Zhang Z (2016) Identification of black tea from four countries by using near-infrared spectroscopy and support vector data description pattern recognition. J Food Sci Technol 11: 337-343.

16. Chen C, Du X (2011) Correlation analysis of main components and quality of Gongfu black tea. Food Sci Technol 26: 83-87.

17. Zhang Y, Jin S, Wang G, Yu L, Zhou S, et al. (2015) Flavor analysis and flavor wheel establishment of ten top famous tea in Zhejiang province. J Tea Sci 35: 225-232.

18. Lawless HT, Heymann H (2010) Sensory evaluation of food principles and practices. Food Eng Ingredient 98: 09.
19. Roberts EAH, Smith RF (1961) Spectrophotometric measurements of theaflavins and thearubigins in black tea liquors in assessment of quality in teas. Analyst 86: 95-98.

20. Ullah MRA (1972) A simplified spectrophotometric method for measuring theaflavins and thearubigins in black tea liquors. Curr Sci 41: 422-423.

21. Biswas AK, Biswas AK, Sarkar AK (1971) Biological and chemical factors affecting the valuation of North East Indian teas. Statistical evaluation of the biochemical constituents and their effects on briskness, quality and cash valuations of black teas. J Sci Food Agric 22: 196-204.

22. Biswas AK, Sarker AR, Biswas AK (1973) Biological and chemical factors affecting the valuation of North East Indian teas: $\square$. Statistical evaluation of the biochemical constituents and their effects on colour, brightness and strength of black teas. J Sci Food Agric 24: 1457-1477.

23. Varnam AH, Sutherland VJ (1994) Beverages: Technology, chemistry and microbiology. Springer, Heidelberg, Germany.

24. Harbowy ME, Balentine DA (1997) Tea chemistry. Crit Rev Plant Chem 16 415-480.

25. Hayashi N, Chen R, Ikezaki H, Ujihara T, Kitajima H, et al. (2007) Evaluation of astringency of black tea by a taste sensor system: Scope and limitation. Biosci Biotechnol Biochem 71: 587-589.

26. Kerio LC, Wachira FN, Wanyoko JK, Rotich MK (2013) Total polyphenols, catechin profiles and antioxidant activity of tea products from purple leaf colored purple tea cultivars. Food Chem 136: 1405-1413.

27. Jiang L, Shen X, Shoji T, Kanda T, Zhou J, et al. (2013) Characterization and activity of anthocyanins in Zijuan tea (Camellia sinensis var. kitamura). J Agric Food Chem 61: 3306-3310.

28. Muthumani T, Senthil Kumar RS (2007) Influence of fermentation time on the development of compounds responsible for quality in black tea. Food Chem 101: 98-102.

29. Horie H, Kohata K (2000) Analysis of tea components by high-performance liquid chromatography and high-performance capillary electrophoresis. J Chromatogr A 881: 425-438.

30. Yao L, Liu X, Jiang Y, Caffin N, D'Arcy B, et al. (2006) Compositional analysis of teas from Australian supermarkets. Food Chem 94: 115-122.

31. Han WY, Li X, Li ZX, Ahammed GJ, Yan P, et al. (2017) Altitudinal effects on the quality of green tea in east China: A climate change perspective. Eur Food Res Technol 243: 323-330.

32. Li Q, Huang J, Liu S, Li J, Yang X, et al. (2011) Proteomic analysis of young leaves at three developmental stages in an albino tea cultivar. Proteome $\mathrm{Sc}$ 9: 44

33. Kottawa-Arachchi JD, Gunasekare MTK, Ranatunga MAB, Punyasiri PAN Jayasinghe L, et al. (2014) Biochemical characteristics of tea (Camellia L. spp.) germplasm accessions in Sri Lanka: Correlation between black tea quality parameters and organoleptic evaluation. Int J Tea Sci 10: 3-13.

34. Wickremasinghe RL, Perera KPWC, Perera VH, Kanapathipillai P (1966) Analysis of polyphenols, amino acids and chlorophyll levels in tea flush at different seasons. Tea Quart 37: 232-235.

35. Liang Y, Lu J, Zhang L, Wu S, Wu Y (2003) Estimation of black tea quality by analysis of chemical composition and colour difference of tea infusions. Food Chem 80: 283-290.

36. Stodt U, Engelhardt UH (2013) Progress in the analysis of selected tea constituents over the past 20 years. Food Res Int 53: 636-648.

37. Stodt UW, Blauth N, Niemann S, Stark J, Pawar V, et al. (2014) Investigation of processes in black tea manufacture through model fermentation (oxidation) experiments. J Agric Food Chem 62: 7854-7861.

38. Roberts EAH, Smith RF (1963) The phenolic substances of manufactured tea: IX The spectrophotometric evaluation of tea liquors. J Sci Food Agric 14: 689-699.

39. Leenen R, Roodenburg AJ, Tijburg LB, Wiseman SA (2000) A single dose of tea with or without milk increases plasma antioxidant activity in humans. Eur $\mathrm{J}$ Clin Nutr 54: 87-92

40. Hollman PCH, Van Het HKH, Tijburg LBM, Katan MB (2001) Addition of milk does not affect the absorption of flavonols from tea in man. Free Radical Res 34: $297-300$. 
Citation: Duan Y, Song X, Yang Y, Li L, Zhao Y, et al. (2018) Preparation and Evaluation of Carrot and Apple Blended Jam. J Food Process Technol 9: 726. doi: 10.4172/2157-7110.1000726

Page 9 of 9

41. Gardner EJ, Ruxton CHS, Leeds AR (2007) Black tea-helpful or harmful? A review of the evidence. Eur J Clin Nutr 61: 3-18.

42. McDowell I, Taylor S, Gay C (1995) The phenolic pigment composition of black tea liquors: Predicting quality. J Sci Food Agric 69: 467-474.

43. Huber LG (2003) Green tea catechins and L-theanine in integrative cancer care: A review of the research. Alternat Complement Therap 9: 294-298.

44. Shahidi F, Naczk M (2004) Phenolics in foods and nutraceuticals. CRC Press, Boca Raton, FL, USA.

45. Scharbert S, Hofmann T (2005) Molecular definition of black tea taste by means of quantitative studies, taste reconstitution, and omission experiments. J Agric Food Chem 53: 5377-5384.

46. Bryan J (2007) Psychological effects of dietary components of tea: Caffeine and L-theanine. Nutr Rev 66: 82-90.
47. Alasalvar C, Pelvan E, Özdemir KS, Kocadağlı T, Mogol BA et al. (2013) Compositional, nutritional, and functional characteristics of instant teas produced from low and high-quality black teas. J Agric Food Chem 61: 7529-7536.

48. Bhattacharyya N, Bandyopadhyay R, Bhuyan M, Tudu B, Ghosh D, et al. (2008) Electronic nose for black tea classification and correlation of measurements with "tea taster" marks. IEEE Trans Instrum Meas 57: 1313-1321.

49. Nobre AC, Rao A, Owen GN (2008) L-theanine, a natural constituent in tea and its effect on mental state. Asia Pac J Clin Nutr 17: 167-168.

50. Sarmah V, Rao LJM (2009) A thought on the biological activities of black tea Crit Rev Food Sci Nutr 49: 379-404.

51. Owuor PO, Obanda M, Nyirenda HE, Mphangwe NIK, Wright LP, et al. (2006) The relationship between some chemical parameters and sensory evaluations for plain black tea produced in Kenya and comparison with similar teas from Malawi and South Africa. Food Chem 97: 644-653. 